\title{
Can simple songs express useful signals for mate choice?
}

\author{
Nan Lyu, Jinlin Li and Yue-Hua Sun*
}

\begin{abstract}
Background: As one of the most elaborate and diverse sexual signals, bird songs are prominent among mate choice criteria. Females generally prefer mates with larger repertoire size, which promotes the evolution of song complexity. However, there are also some songbirds that have far simpler and less diverse vocalizations, which have not been the focus of scientific scrutiny. Most Phylloscopus warblers are accomplished singers with complex songs. In contrast, Hume's Warbler (P. humei) has extremely simple songs. In order to explore the song's function, its evolutionary significance and particularly to assess its possible relationship with parental investment, we studied mate choice of the subspecies P. h. mandellii in Lianhuashan National Nature Reserve, Gansu, China.

Methods: We recorded body measurements and songs of breeding males and then explored their relationships with the date of clutch initiation, reasoning that the characteristics of males that are involved with early nesting activities reflect female mate preferences. We also recorded egg size and body measurements of nestlings to assess the relationship between parental investment and mate choice.

Results: We found that male wing and tail lengths were positively correlated with early clutch initiation as were songs characterized by short duration and rapid rise to maximum amplitude. We also found that early-breeding females did not lay large eggs, but produced more surviving young, which grew up faster.

Conclusions: Female mate choice criteria in this bird include both visual signals and song characteristics. Our study supports the hypothesis that females may judge male quality from quite subtle differences. In order to reduce the risk of predation, a preference for such inconspicuous male characteristics may be partially driven by high vulnerability of this warbler to predators as a ground-nesting species.
\end{abstract}

Keywords: Bird song, Sexual selection, Mate choice, Parental investment, Hume's Warbler

\section{Background}

Mate choice is one of the main sexual selection mechanisms and can lead to the evolution of conspicuous or even excessive phenotypic characteristics in animals (Andersson 1994). Bird songs tend to be long and complex vocalizations produced by male individuals during the breeding season (Catchpole and Slater 2008) and are prominent criteria in the mate choice (Searcy and Andersson 1986). Females generally prefer mates with a large sized repertoire, promoting the evolution of song complexity (Searcy 1992). In contrast, some songbirds

*Correspondence: sunyh@ioz.ac.cn

Key Laboratory of Animal Ecology and Conservation Biology, Institute

of Zoology, Chinese Academy of Sciences, Beijing 100101, China have far simpler and less diverse vocalizations (Byers and Kroodsma 2009). The function and evolution of such "simple songs" and their relationship to sexual selection have attracted little attention (Cardoso and $\mathrm{Hu}$ 2011) and our understanding of mate choice of these species is therefore limited, besides its potential significance to the exploration of avian song evolution.

Generally in nature, conflicting pressures of sexual selection as well as in natural selection have long been viewed as a means to stabilize the evolution of sexually selected signals, such as ornaments and songs in birds (Andersson 1994; Gray and Cade 1999). Females can reap benefits both directly and indirectly through an appropriate mate choice (Møller and Thornhill 1998), e.g., getting better food resources, nest sites, nuptial gifts and also 
better genes for their offspring. Furthermore, parental investment strategies of both sexes may be influenced by their choice in mates, which in turn affects the survival of their offspring (Mitchell et al. 2007; Ligon and Hill 2010). For example, female Common Moorhens (Gallinula chloropus) compete for relatively fat males that are more persistent incubators (Petrie 1983), while female Common Stonechats (Saxicola torquata) prefer males with higher song rates, which apparently signals that they are more diligent in feeding offspring and in nest defense (Greig-Smith 1982). Male Great Tits (Parus major) with a large central black breast-stripe are also more likely to defend their brood (Norris 1990). Moreover, females can alter egg size (e.g. Cunningham and Russell 2000; Rutstein et al. 2004; Bonato et al. 2009) or feeding effort (e.g. Linville et al. 1998; Ligon and Hill 2010) according to the quality of their mates.

Most of the Phylloscopus warblers are accomplished singers with remarkable and impressive songs. In the Hume's Warbler (P. humei), however, only two simple songs have been reported (Baker 1997). They are described either as a double whistle note or as a drawnout descending buzz. Furthermore, for $P$. $h$. mandellii, it had been discovered that this subspecies only issues the buzz song type (Fig. 1), but has five types of call (Bi 2004). It is still unclear why the songs of $P$. hume $i$ are so different from other apparently closely related Phylloscopus species (Baker 1997; Bi 2004).

Phylloscopus humei was originally considered as conspecific under the name of Yellow-browed Warbler $P$. inornatus (Voous 1977) but, based on acoustic, molecular, morphological and behavioral evidence, it is now accorded full species status (Irwin et al. 2001). Two disjunct subspecies are recognized: $P . h$. humei in India and $P . h$. mandellii in central China (Baker 1997). It is monomorphic, lacking obvious sexual ornaments but males, competing for territories early in the breeding season, display their pale wing-bars in $P$. h. humei (Marchetti 1993, 1998). Hitherto, only some basic descriptions about population status and breeding are available for the
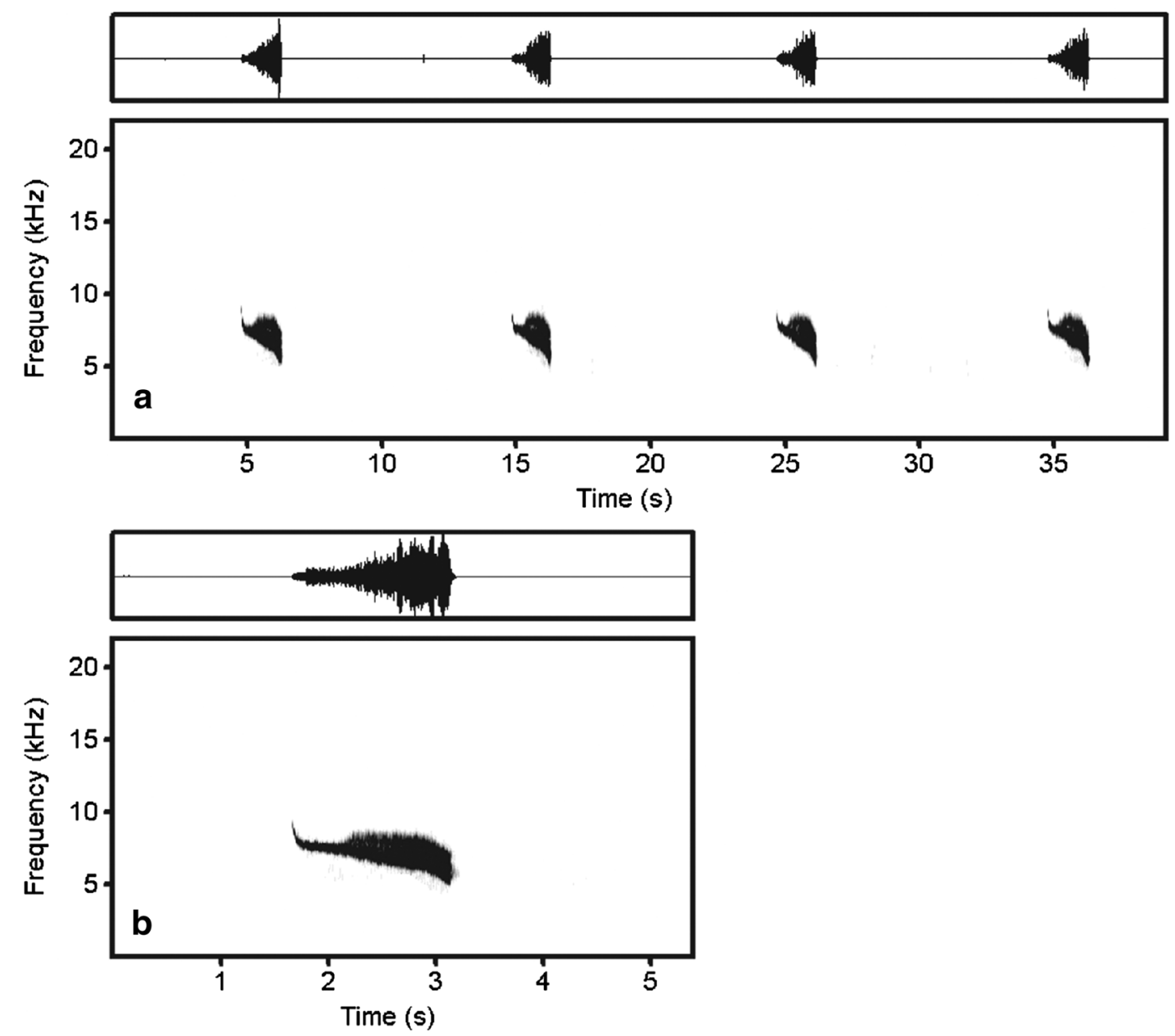

Fig. 1 Song spectrogram of P. h. mandellii. $\mathbf{b}$ is the magnified spectrogram of the third note in $\mathbf{a}$ 
Chinese subspecies (Bi et al. 2009). In order to explore the possible relationships between mate choice and the simple song of $P$. humei, we conducted a field study of $P$. h. mandellii in the Lianhuashan Nature Reserve, Gansu, China. We specifically studied (1) preferences of females in their mate choice (considering both visual and song characteristics) and (2) whether the survival and development of their offspring is related to their mate choice.

\section{Methods}

We studied breeding $P$. h. mandellii birds at Shahetan station in the Lianhuashan National Nature Reserve $\left(34^{\circ} 40^{\prime} 67^{\prime \prime} \mathrm{N}, 103^{\circ} 30^{\prime} 84^{\prime \prime} \mathrm{E}\right)$ during the April-July periods in 2009 and 2010. The elevation of the station is $2850 \mathrm{~m}$ asl. Mature mixed forests throughout the study area are dominated by spruce, fir, willow and birch trees (Sun et al. 2003). Local ground vegetation varies from sparse vegetation to dense shrubs of different species, as well as grasses, Arrow Bamboo (Sinarundinaria nitida), forbs and mosses (Sun et al. 2003).

We captured a total of 55 males using mist nets and marked them with unique combinations of colored leg bands to facilitate field identification. We captured male individuals as soon as possible when we detected their singing at the beginning of the breeding season (from late April to the middle of May). We opted for three types of measurements, i.e., body characteristics, ornamental and song characteristics to assess the relationship with female mate preferences. Specifically, we measured (1) bill length (exposed culmen), wing length, tail length and tarsus length as body characteristics using a centimeter ruler to the nearest $0.1 \mathrm{~mm}$; (2) eyebrow size and wingbar size (= length $\times$ width) as the ornamental characteristics using vernier calipers to the nearest $0.1 \mathrm{~mm}$. We also recorded songs from differently marked males using a Sony WM-D6 recorder and a Sennheiser directional microphone. Song recording would be conducted at least 1 day after capture. A total of 139 recordings were analyzed using Avisoft SASLab Pro v. 4.52 applying the following settings: sampling frequency $22,050 \mathrm{~Hz}, 16 \mathrm{bit}$, time resolution $5.8 \mathrm{~ms}$ and bandwidth $162 \mathrm{~Hz}$. In order to remove background sounds (the noises and sounds of other birds), all recordings were filtered using the FIR high-pass filter in the software with a low frequency limit of $4.5 \mathrm{kHz}$ before our analyses. We measured the following song parameters: duration (DUR), interval (INT), maximum amplitude (MA), distance from start to maximum amplitude (DSM), maximum frequency in the maximum amplitude (MAXMA), minimum frequency in the maximum amplitude (MINMA), frequency bandwidth in the maximum amplitude (FBMA), maximum frequency (MAXF), minimum frequency (MINF) and frequency bandwidth (FB).
We found nests by following females during the nest building period (mainly from late May to early June) and checked daily to measure the length, width and mass of newly laid eggs. In order to minimize disturbance when following females, we would check the nest after the female left. This bird has strong territorial defense behavior throughout the breeding period. In order to determine the ownership of the nest by the male, we would identify the territory of each male bird according to our field observation and as well check the color rings of male birds to verify the ownership during the incubation and/ or nestling period. All nests laid eggs successfully. We calculated the egg volume as $0.457 \times$ length $\times$ width $^{2} / 1000$ (Hoyt 1979). Following Marchetti (1998), we used the first egg date as a quantitative measure of female mate preference (i.e., females preferred the characteristics of males who supported the earliest possible nestings). Since the nestling period of $P$. $h$. mandellii is about 14 days (Bi et al. 2009), we measured the nestlings on Day 12 (bill length, wing length, tail length and tarsus length) to assess the development during the nestling period.

In order to identify the relationships among the characteristics of the body of males, egg size and fledging size, we applied a Generalized Linear Model (GLM) using R (version 2.14.1). Since multi-collinearity of independent variables can cause problems in regression models (Hosmer and Stanley 2000), we first calculated the bivariate correlations among different variables and then used a correlation coefficient threshold of 0.7 as suggested by Fielding and Haworth (1995). Fifteen variables were retained for further analysis, i.e., bill length, wing length, tail length, weight, tarsus length, eyebrow size, wing bar size, DUR, INT, DSM, MA, MAXMA, FBMA, MINF and FB. We conducted simple regression models for these variables and excluded nonsignificant variables $(p>0.05)$. Subsequently, we used a multiple regression model containing all significant variables and applied a stepwise backward procedure based on Akaike's information criterion (AIC, Akaike 1974) in order to reduce the number of variables.

\section{Results}

During the 2 years of field work, we found 25 nests of the 55 captured males and another 18 nests of $P$. h. mandellii without capturing the male owners. From a total of 43 nests, we identified 40 with first egg laying dates, of which 18 reared at least two fledglings successfully. None of the nests were deserted in 2009, while two nests were deserted during the egg laying period and incubation period in 2010. This may be related to the harsh climate with continuous rain during 2010. Basic information about male characteristics, eggs and nestlings are presented in Additional file 1: Tables S1 and S2. 


\section{Female mate choice}

First egg dates were May 24 in 2009 and May 28 in 2010. In order to quantify the preference for a mate by a female individual, we defined these days as " 1 " and then transformed the first egg dates of the various nests into a numerical format $(D)$. Five variables were significant $(p<0.05)$ in the simple regression analyses (Table 1$)$. The DSM, FBMA and wing length have the highest explanatory power, with relatively large $F$ values. The best multiple regression model only retained two of the five predictor variables entered $\left(F_{2,16}=14.275\right.$, $p<0.001$ ), i.e., DSM and wing length (Table 1), which represent the song and body size characteristics, respectively. The DSM affected the egg laying date positively, while the wing length was negatively correlated with $D$ (Fig. 2). Furthermore, we found that the wing-bar size was significantly correlated with wing length $(r=0.513$, $n=54, p<0.001)$.

\section{Relationships between mate choice and offspring}

Egg volume was correlated with egg mass $(r=0.929$, $n=188, p<0.001)$. Neither the mean egg mass $\left(F_{1,17}=0.286, p=0.600\right)$ nor egg volume $\left(F_{1,17}=0.124\right.$, $p=0.729)$ were significantly correlated with first egg laying dates. However, the nestling bill length at Day 12 was negatively correlated with the first egg laying date $\left(F_{1,13}=12.47, p=0.004\right.$; Fig. $\left.3 a\right)$, suggesting that early nesting may confer benefits for the offspring. Further, nestling size was correlated with egg size, given that bill length was positively correlated with egg volume $\left(F_{1,16}=10.11, p=0.006\right.$; Fig. 3b).

\section{Discussion}

The evolution of sexual phenotypic characteristics is affected not only by sexual selection, but also by natural selection (Andersson 1982). Highly developed secondary sexual characteristics generally require large investments

Table 1 Results of the mate choice of P. h. mandellii birds

\begin{tabular}{|c|c|c|c|c|c|c|c|c|}
\hline \multirow[t]{2}{*}{ Variables } & \multicolumn{4}{|c|}{ Simple regression models } & \multicolumn{4}{|l|}{ GLM } \\
\hline & Estimate & SE & $F_{1,17}$ & $p$ & Estimate & SE & $t$ & $p$ \\
\hline Intercept & & & & & 19.803 & 16.913 & 1.171 & 0.259 \\
\hline Wing length & -9.544 & 2.804 & 6.808 & 0.002 & -4.650 & 2.625 & -1.771 & 0.096 \\
\hline Tail length & -5.821 & 2.782 & 1.002 & 0.048 & & & & \\
\hline DUR & 11.542 & 5.153 & 5.016 & 0.039 & & & & \\
\hline DSM & 13.951 & 2.936 & 22.57 & $<0.001$ & 11.915 & 2.997 & 3.976 & 0.001 \\
\hline FBMA & 5.693 & 1.842 & 9.536 & 0.007 & & & & \\
\hline
\end{tabular}

Only significant variables $(p<0.05)$ are listed. We report the estimated coefficients (Estimate), standard error (SE), $t$ values and $p$ values from GLM with step backward analysis
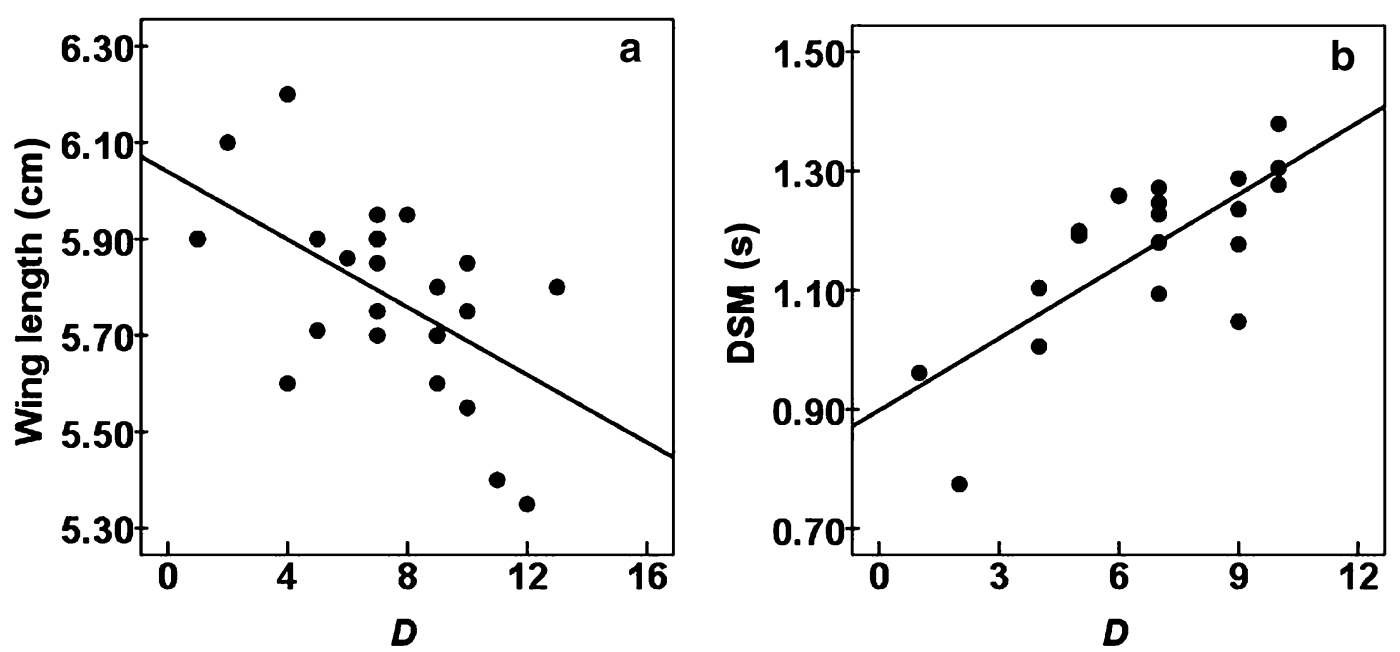

Fig. 2 Associations of male characteristics with criteria in female mate preferences (laying date) for P. $h$. mandellii. $D$ represents the laying date of the first egg and DSM the distance from start to maximum amplitude. a Regression of laying date on wing length; $\mathbf{b}$ regression of laying date on DSM 

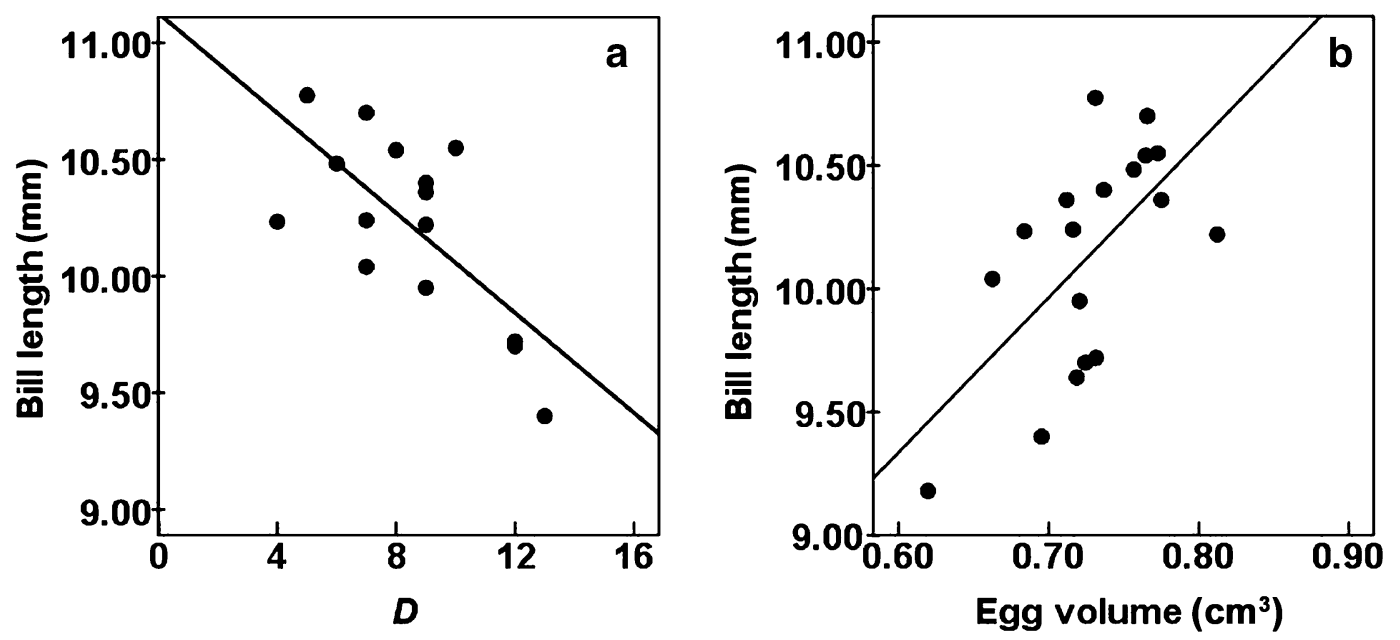

Fig. 3 Association of bill lengths of fledglings with criteria in female mate preferences (laying date) and egg volume for P. h. mandellii. a Regression of fledglings' bill length on laying date; $\boldsymbol{b}$ egg volume

in energy and attract predators. In either case, survival and both current and future reproduction may be adversely affected (Gray and Cade 1999).

As in P. h. humei (Marchetti 1998), we found that the criteria females use in their choice of a mate in $P . h$. mandellii include both visual signals (e.g. wing length) and song characteristics. We suggest that this phenomenon is also a joint action of natural and sexual selection (Höglund and Sheldon 1998; Kokko et al. 2002). In general, two hypotheses may be applied to explain the evolution of this type of mate choice and simple songs. First, Gilliard's 'transfer hypothesis' suggests that bright ornaments and other secondary sexual characteristics (including passerine songs) may be inversely related (Gilliard 1956); e.g., males of more dimorphic species have a dominant tendency to sing short songs in 56 North American wood warblers (Parulinae) (Shutler and Weatherhead 1990). However, P. h. mandellii obviously does not satisfy this hypothesis, for it has quite simple songs and its plumage is even less ornamental than that of other sympatric Phylloscopus spp., (e.g., P. kansuensis with a bright median crown stripe and yellow rump).

Generally, over-developed secondary sexual characteristics may require large amounts of energy and increase predation risks (Andersson 1994), which therefore should be more costly. Another proposed explanation is that females may judge male quality from quite subtle differences, such as small variations in male songs (Forstmeier et al. 2002) or slight variations in visual signals, such as eye ring pigmentation (Pérez-Rodríguez 2008), wing patch size (Török et al. 2003) or badge size (Griffith 2000). These types of criteria in females in mate choice can clearly reduce risk of predation. For $P$. $h$. mandellii females in particular, we suggest that these criteria of inconspicuous visual signals (e.g., longer wing and tail lengths) and short, inconspicuous songs may be partially related to their nesting behavior. As a ground nester, their inconspicuousness and monomorphism may be especially advantageous, as has been suggested for groundnesting wood warblers as well (Shutler and Weatherhead 1990). Therefore, in order to reduce the probability of nest predation, $P$. $h$. mandellii may have evolved specific mate choice preferences in females for longer wings and smaller DSM (Fig. 2). Furthermore, given the statistically significant correlation between wing-bar size and wing length, we suggest that this bird may identify male size through the wing-bar, which should be rather easier to distinguish among individual males, as indicated in $P$. $h$. humei (Marchetti 1998).

With regard to song, we found that the first egg laying date was correlated with the parameters related to maximum amplitude, such as DSM, FBMA and MINMA. The most significant parameter was DSM, with early breeders having relatively short DSMs. Moreover, DUR was negatively correlated with first egg dates and DSM, suggesting that females prefer males whose songs are shorter with a faster increase in volume. Contrary to the study on $P . h$. humei by Marchetti (1998), we found that the song rate $(=1 / \mathrm{INT})$ was not correlated with the first egg date. This may be related to the multiple mate selection criteria and high plasticity in Hume's Warbler. Marchetti (1998) also found that the egg laying date was no longer correlated with song rate when wing-bar size was altered artificially. Furthermore, male songs have another important role in territorial defense. Catchpole (1983) has proposed that long songs may serve to attract mates while short songs 
are used for territorial defence. The shortness of territorial defence songs could be attributed to the need in males to hear the response of their competitors (Ince and Slater 1985). We accordingly suggest that the simple song of $P$. $h$. mandellii should play an important role in the defence of territory.

Finally, it should be stated that although females of $P$. h. mandellii in our study did not vary their investment in eggs in relation to the first egg laying date (i.e., mate choice), we obtained some evidence of faster growth in earlier hatched nestlings. This suggests that such chicks may have benefitted from higher rates of feeding or from better food. We observed that both parents bring food and feed the nestlings cooperatively. Therefore, we suggest that the female preference for larger males (i.e., longer-winged individuals) may be driven by the greater ability of such males to provision their young. Alternatively, these individuals may be more likely to occupy better territories with better food resources and/or better nest sites. Any or all of these features should play an important role in promoting the growth of their offspring and breeding success.

\section{Additional file}

Additional file 1: Table S1. Three types of measurements for captured males including body characters, ornamental and song characters. Table S2. The measurements of eggs and nestling.

\section{Authors' contributions}

$\mathrm{NL}$ and $\mathrm{YHS}$ designed the study. NL and $J \mathrm{~L}$ collected the data and performed all analyses. NL and YHS drafted the manuscript. All authors read and approved the final manuscript.

\section{Acknowledgements}

This work was supported by the National Natural Sciences Foundation of China (Grant Nos. 31301886, 31272286). We sincerely thank Peipeng Luo and Yingxin Jiang for their great help in the field. We also thank Yi Tao, Chenxi Jia, Wenqin Zhong and Dan Strickland for their helpful comments.

\section{Competing interests}

The authors declare that they have no competing interests.

Received: 16 October 2015 Accepted: 12 May 2016

Published online: 14 June 2016

\section{References}

Akaike H. A new look at the statistical model identification. IEEE Trans Automat Contr. 1974;19:716-23.

Andersson M. Sexual selection. Princeton: Princeton University Press; 1994.

Andersson M. Female choice selects for extreme tail length in a widowbird. Nature. 1982;299:818-20.

Baker K. Warblers of Europe, Asia and North Africa. Princeton: Princeton University Press; 1997.

Bi Z-L. Study on the vocalizations, breeding ecology and nest evolution of Phylloscopus genus. Ph.D. thesis. Institute of Zoology, Chinese Academy of Sciences; 2004

Bi Z-L, Sun Y-H, Jiang Y-X, Jia C-X. Breeding notes and incubation behavior of Phylloscopus humei at Lianhuashan in Gansu. Chin J Zool. 2009;44:14-8.
Bonato M, Evans MR, Cherry MI. Investment in eggs is influenced by male coloration in the ostrich, Struthio camelus. Anim Behav. 2009;77:1027-32.

Byers BE, Kroodsma DE. Female mate choice and songbird song repertoires. Anim Behav. 2009;77:13-22.

Cardoso GC, Hu Y. Birdsong performance and the evolution of simple (rather than elaborate) sexual signals. Am Nat. 2011;178:679-86.

Catchpole CK, Slater PJB. Bird song: biological themes and variations. 2nd ed. Cambridge: Cambridge University Press; 2008.

Catchpole CK. Variation in the song of the Great Reed Warbler Acrocephalus arundinaceus in relation to mate attraction and territorial defense. Anim Behav. 1983;31:1217-25.

Cunningham EJA, Russell AF. Egg investment is influenced by male attractiveness in the mallard. Nature. 2000;404:74-7.

Fielding $\mathrm{AH}$, Haworth PF. Testing the generality of bird-habitat models. Conserv Biol. 1995;9:1466-81.

Forstmeier W, Kempenaers B, Meyer A, Leisler B. A novel song parameter correlates with extra-pair paternity and reflects male longevity. Proc $\mathrm{R} S \mathrm{Soc} B$ Biol Sci. 2002;269:1479-85.

Gilliard T. Bower ornamentation versus plumage characters in bower-birds. Auk. 1956:73:450-1.

Gray DA, Cade WH. Sex, death and genetic variation: natural and sexual selection on cricket song. Proc R Soc B Biol Sci. 1999;266:707-9.

Greig-Smith P. Song-rates and parental care by individual male stonechats (Saxicola torquata). Anim Behav. 1982;30:245-52.

Griffith SC. A trade-off between reproduction and a condition-dependent sexually selected ornament in the house sparrow Passer domesticus. Proc R Soc B-Biol Sci. 2000:267:1115-9.

Höglund J, Sheldon BC. The cost of reproduction and sexual selection. Oikos. 1998:83:478-83.

Hosmer DW, Stanley L. Applied logistic regression. New York: Wiley; 2000.

Hoyt DF. Practical methods of estimating volume and fresh weight of bird eggs. Auk. 1979;96:73-7.

Ince SA, Slater PJB. Versatility and continuity in the song of thrushes Turdus spp. Ibis. 1985;127:355-64.

Irwin DE, Alstrom P, Olsson U, Benowitz-Fredericks ZM. Cryptic species in the genus Phylloscopus (Old World leaf warblers). Ibis. 2001;143:233-47.

Kokko H, Brooks R, McNamara JM, Houston Al. The sexual selection continuum. Proc R Soc B Biol Sci. 2002;269:1331-40.

Ligon RA, Hill GE. Sex-biased parental investment is correlated with mate ornamentation in eastern bluebirds. Anim Behav. 2010;79:727-34.

Linville SU, Breitwisch R, Schilling AMYJ. Plumage brightness as an indicator of parental care in northern cardinals. Anim Behav. 1998:55:119-27.

Marchetti K. Dark habitats and bright birds illustrate the role of the environment in species divergence. Nature. 1993;362:149-52.

Marchetti K. The evolution of multiple male traits in the yellow-browed leaf warbler. Anim Behav. 1998:55:361-76.

Mitchell DP, Dunn PO, Whittingham LA, Freeman-Gallant CR. Attractive males provide less parental care in two populations of the common yellowthroat. Anim Behav. 2007;73:165-70.

Møller AP, Thornhill R. Male parental care, differential parental investment by females and sexual selection. Anim Behav. 1998;55:1507-15.

Norris K. Female choice and the quality of parental care in the great tit Parus major. Behav Ecol Sociobiol. 1990;27:275-81.

Pérez-Rodríguez L. Carotenoid-based ornamentation as a dynamic but consistent individual trait. Behav Ecol Sociobiol. 2008:62:995-1005.

Petrie M. Female moorhens compete for small fat males. Science. 1983;220:413-5.

Rutstein A, Gilbert L, Slater P, Graves J. Mate attractiveness and primary resource allocation in the zebra finch. Anim Behav. 2004;68:1087-94.

Searcy WA, Andersson M. Sexual selection and the evolution of song. Annu Rev Ecol Syst. 1986;17:507-33.

Searcy WA. Song repertoire and mate choice in birds. Am Zool. 1992:32:71-80.

Shutler D, Weatherhead PJ. Targets of sexual selection: song and plumage of Wood Warblers. Evolution. 1990;44:1967-77.

Sun Y-H, Swenson JE, Fang Y, Klaus S, Scherzinger W. Population ecology of the Chinese grouse, Bonasa sewerzowi, in a fragmented landscape. Biol Conserv. 2003;110:177-84.

Török J, Hegyi G, Garamszegi LZ. Depigmented wing patch size is a conditiondependent indicator of viability in male collared flycatchers. Behav Ecol. 2003;14:382-8.

Voous KH. List of recent holarctic bird passerines. Ibis. 1977;119:376-406. 